\title{
Submerged micro grinding: a metalworking fluid application study
}

\author{
Peter A. Arrabiyeh ${ }^{1} \cdot$ Marius Heintz $^{1} \cdot$ Sonja Kieren-Ehses ${ }^{1} \cdot$ Martin Bohley $^{1} \cdot$ Benjamin Kirsch $^{1}$ - Jan C. Aurich ${ }^{1}$
}

Received: 2 December 2019 / Accepted: 23 March 2020/Published online: 22 April 2020

(C) The Author(s) 2020

\begin{abstract}
Micro machining with micro pencil grinding tools (MPGTs) is an emerging technology that can be used to manufacture closed microchannel structures in hard and brittle materials as well as hardened steels like $16 \mathrm{MnCr} 5$. At their current operating conditions, these tools have a comparatively short tool life. In previous works, MPGTs in combination with a minimum quantity lubrication (MQL) system were used to manufacture microchannels in $16 \mathrm{MnCr} 5$ hardened steel. The study has shown that steel adhesions clog the abrasive layer of MPGTs, most likely resulting from insufficient lubrication. In this paper, a metalworking fluid (MWF) supply method was developed to improve the process: a submerged micro grinding process, in which machining takes place inside a pool of MWF. In this study, the effect of seven types of MWFs on material adhesions at the bottom surface of the tool is evaluated. Equivalent good MWFs are then compared in a micro pendulum grinding experiment till failure.
\end{abstract}

Keywords Micro pencil grinding tools $\cdot$ Micro grinding $\cdot$ Metalworking fluid $\cdot$ Submerged cutting $\cdot$ Electroless plating · Microstructures

\section{Introduction}

Manufacturing technology is continuously being improved with respect to the precision [1] of its produced goods. Producing smaller and lighter products that can integrate more functions in their given product size is becoming more feasible as research progresses [2]. An example for such products is the emerging trend of using the lab-on-a-chip technologya deoxyribonucleic acid (DNA) sequencing micro total analysis system that can replace a conventional lab for a quick analysis [3], all while being small enough to fit in your pocket.

Common non-cutting micromanufacturing techniques are, for example, laser (light amplification by stimulated emission of radiation), EDM (electric discharge machining), FIB (focused ion beam) photolithography, chemical etching, and LIGA (lithography, electroplating, and molding) [4]. Micro cutting techniques are essentially scaled down conventional processes combined with high-end precision machine tools. The most commonly used micro cutting processes are micro

Peter A. Arrabiyeh

Peter.Arrabiyeh@mv.uni-kl.de

1 Institute for Manufacturing Technology and Production Systems, TUK Technische Universität Kaiserslautern, P.O. Box 3049, 67653 Kaiserslautern, Germany turning, micro milling, micro drilling, and micro grinding. Single-edged micro end mills and micro drills are usually made out of cemented carbide and are used to machine a wide range of ductile materials. Micro end mills are microstructuring tools that are available in various geometrical shapes and can be scaled down to diameters of less than $6 \mu \mathrm{m}$ [5], while micro drills can be scaled down to $5 \mu \mathrm{m}$ [6].

There are two types of micro grinding tools: dicing blades and micro pencil grinding tools (MPGTs) [7]. Dicing blades are thin grinding wheels with thicknesses down to $10 \mu \mathrm{m}$ [8], which are mainly used in the semiconductor industry to cut wafers [9]; recently they have also been used to machine micro tools [10]. MPGTs are pin-like microstructuring tools that are coated with superabrasives like diamond and cBN (cubic boron nitride) to machine microchannels into hard and brittle materials with channel widths down to $5 \mu \mathrm{m}$ [11]. While dicing blades are mainly used to manufacture open microstructures, MPGTs can manufacture both open and closed microstructures [7].

In grinding processes, the cutting edges of stochastically distributed superabrasives realize the material removal. These abrasive grits come in different shapes, grit sizes, and adhere to random positions on the tool with different grit distributions. The chip thickness of material removed by each grit is, therefore, different prompting a high proportion of grits only to provoke elastic and plastic deformation, producing a lot of frictional heat [12]. The resulting high-cutting 
temperatures lead to problems such as poor dimension accuracy [13], a high thermal strain on the workpiece surface that causes material structure changes as well as high tensile stresses [12], and a high wear rate of the grinding tool [13]. Four types of tool wear categories can occur during machining; tribochemical reactions (diffusion, oxidation), adhesion, abrasion, and crack formation [14]. Feng conducted micro grinding experiments to identify profile changes of diamond grits over the tool life cycle, by inspecting each grit at the bottom surface of MPGTs before and after machining a microchannel. He observed that grits at the center of the tool were more prone to abrasive wear because the grits closer to the pivot are more involved in scratching than in cutting operations. The grits on the outer periphery of MPGTs that do most of the cutting showed more grit fractures, due to higher mechanical impacts [2].

Cracks on cutting edges are usually the result of alternating loads during a cutting process that happens due to an interrupted cut. Adhesions occur for given cutting edge/workpiece pairings due to high process forces and high process temperatures [14]. Adhesions become a problem when they clog the abrasive layer of MPGTs or form buildup edges on abrasive grits. In experiments conducted at our institute, the clogging of the abrasive layer became apparent when machining non-brittle materials like hardened $16 \mathrm{MnCr} 5$ steel workpieces. The abrasive layer of utilized MPGTs was clogged with steel adhesions whenever dry machining was done. Adhesions have a strong bond with the abrasive layer; if removed, a portion of the abrasive layer is also detached off its base body [15]. In micro milling, adhesions come in the form of build-up edges that occur on the cutting edges of micro end mills when machining ductile metallic workpieces [16].

Metalworking fluids (MWFs) have the task to dissipate heat, reduce friction, and support the transport of chips from the machining zone [17]. Using MWFs that are suitable for a given tool/workpiece pair, leads to better chip formation, lower cutting forces, better process stability, and improved surface quality for machined workpieces [14]; ultimately, they prevent or inhibit the aforementioned tool wear mechanisms.

When compared with conventional machining, only small steps have been done researching MWFs in micro machining. The most common supply method is using the minimum quantity lubrication (MQL) method. MQL-based processes supply the machining process with only small quantities of MWF and air - quantities of less than $50 \mathrm{ml} / \mathrm{h}$. This MWF supply method was introduced to reduce harm to the environment [18]. Of course, for a micro machining process, $50 \mathrm{ml} / \mathrm{h}$ can be considered a flood supply of MWF when compared with conventional scales [15]. One of the most widespread practices is using an MQL supplying method in combination with nanofluids - a water- or oil-based fluid that usually contains a surfactant and nanoparticles made out of graphite, aluminum oxide, or diamond to increase the thermal conductivity of the MWF via the ball bearing effect [19]. Ionic fluids combined with a MQL system have also been used in micro machining processes, reducing both the process forces and the surface quality of machined workpieces; however, the results did not improve upon available MWFs [20]. In a micro grinding experiment, air cooling was used instead of MWFs, while the process proved to be functional, commercially available MWFs outperformed air cooling by far, reaching about five times the tool life [13].

At our institute, micro grinding experiments with electroless plated MPGTs (diameter $50 \mu \mathrm{m}$ ) in $16 \mathrm{MnCr} 5$ steel workpieces were conducted using the MQL method with a MWF made out of distilled water and $0.02 \mathrm{wt} . \%$ of sodium dodecyl sulfate (SDS). This MWF was compared with dry machining and experiments with distilled water as a coolant. The experiments conducted with SDS were the only ones where the tool managed to machine the assigned cutting path of $0.5 \mathrm{~mm}$ [15]; however, the tools suffered from high amounts of adhesions and flattened abrasive grits, indicating high process temperatures [21]. In a follow-up study, an SDS solution, isopropanol, and the commercially available synthetic oil DiaMond 80 were used via MQL in a micro milling experiment. The tools used in combination with DiaMond 80 exhibited the lowest amount of adhesions on the cutting edge and produced the best surface quality in the machined microchannels [16].

Zhang introduced another cooling method in his technical report in 1995: submerged cutting - a process in which the machining takes place in a pool of MWF [22]. Brudek compared the MQL system with submerged cutting for micro milling. He compared the commercially available MWFs called Lubrimax Edel C and Avantin $408 \mathrm{Neu}$ to canola oil and sesame oil. While canola oil and Lubrimax Edel C outperformed the other two MWFs, the supply method had little influence on the surface roughness of machined workpieces [23]. However, no tool life tests were performed.

In recent observations, blue brittleness was observed on the bottom of micro channels machined with the MQL system, which suggests that the micro grinding process at our institute is constantly operating under high temperatures. A continuous supply of MWF that can be achieved with submerged cutting can lead to a huge benefit for the tool life of MPGTs. In this paper, submerged cutting will be introduced for a micro grinding process with electroless plated $50 \mu \mathrm{m}$ MPGTs that have a grit size of $5-10 \mu \mathrm{m}$. Just as in the previous research, the workpiece material will be hardened $16 \mathrm{MnCr} 5$ (665 HV30). This study compares seven types of MWFs in total. To validate the new MWF supplying method, the previously used surfactant SDS will be mixed with distilled water in concentrations of 1 wt. $\%$ and 5 wt.\%. DiaMond 80, the MWF that reduced the formation of build-up edges in previous micro milling experiments, will also be examined. The study also aims to test the effect of Lubrimax Edel C and canola oil on 
this micro grinding process-MWFs that were used by other researchers. Finally, Petrofer Isocut R10 - HM, a MWF used for conventional grinding operations at our institute, and Twinmax, a highly viscous plant-based oil from the company Steidle (the same manufacturer as Lubrimax Edel C), are also going to be used.

\section{Experimental setup}

The investigations were carried out on an ultra-precision fouraxis desktop machine (Fig. 1) that is mounted on top of a vibration isolated granite plate. The machine tool consists of a spindle, a camera system, three linear axes $(X, Y, Z)$ and a rotational axis $(A)$ that allows the spindle to rotate around the $Y$-axis. Both the spindle and the $A$-axis are mounted on the $Z$ axis. The $Z$-axis has a travel of $101.6 \mathrm{~mm}$, is guided by crossrollers, and is powered by a stepper motor at a resolution of $2.54 \mathrm{~nm}$. The rotational axis is driven by a harmonic drive system that allows the spindle to rotate $\pm 30^{\circ}$ around the $Y$ axis at a resolution of $0.00045^{\circ}$. The $X-Y$ table has a $100-\mathrm{mm}$ travel, is guided by an air bearing system, and is powered by a

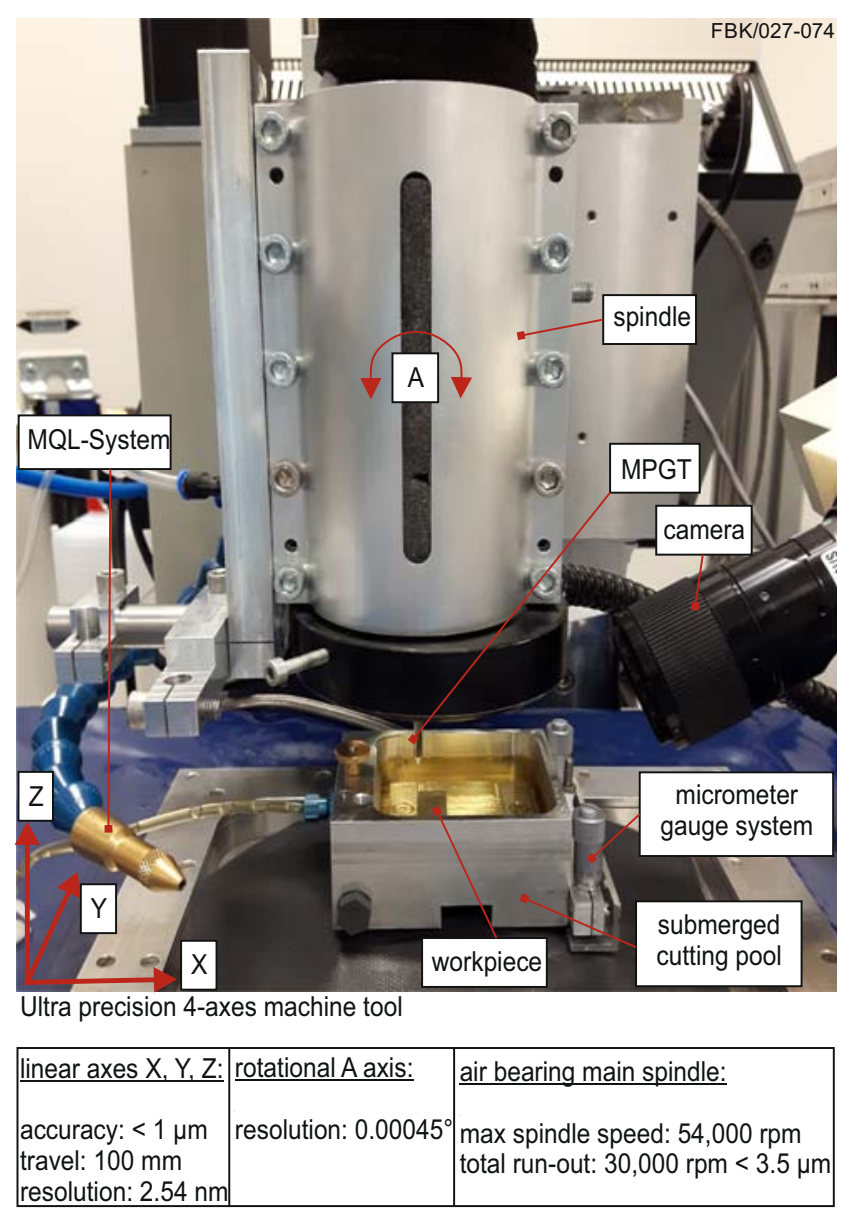

Fig. 1 Ultra-precision four-axis desktop machine stepper motor at a resolution of $2.54 \mathrm{~nm}$. All linear axes have a positioning accuracy $<1 \mu \mathrm{m}$.

The rotational speed of the air bearing spindle can be varied in a range of 5000-54,000 rpm. In this paper, a rotational speed of 30,000 rpm was used for the experiments, which resulted in a total run-out error of $3.5 \mu \mathrm{m}$ on the clamped tool. A manually adjustable clamping system helped to reduce runout errors to a minimum.

The workpieces used for this investigation were made of $16 \mathrm{MnCr} 5$ hardened steel with a hardness of $665 \mathrm{HV} 30 \pm 15$ HV30. A polishing process is used to prepare the surface of the workpieces. The workpieces are glued to a mounting plate that is fixed in the submerged cutting pool. The two micrometer gauges are used to align the workpiece.

The bottom surfaces of the microchannels were analyzed using a confocal microscope (Nanofocus $\mu$ surf) with a $\times 60$ magnification lens and a numerical aperture of $\mathrm{NA}=0.9$. Confocal analysis was done to measure the depth of each microchannel. The roughness was not considered because the influence of tool specification outweighs the effect of MWFs.

\section{Experimental procedure}

\subsection{Process kinematics and experimental plan for adhesion tests}

Figure 2 depicts the process kinematics and the parameters used in this study. The MPGT rotates clockwise around its axis at a 30,000 rpm, and the workpiece moves towards the MPGT at a feed rate of $1 \mathrm{~mm} / \mathrm{min}$. These process kinematics were used to validate the functionality of the submerged cutting pool and to determine the effect different MWFs have on the formation of adhesions. Seven MWFs have been chosen for this study (Table 1): SDS (1 wt.\%), SDS (5 wt.\%), DiaMond 80, Petrofer Isocut R10 - HM, canola oil, Lubrimax Edel C, and Twinmax.

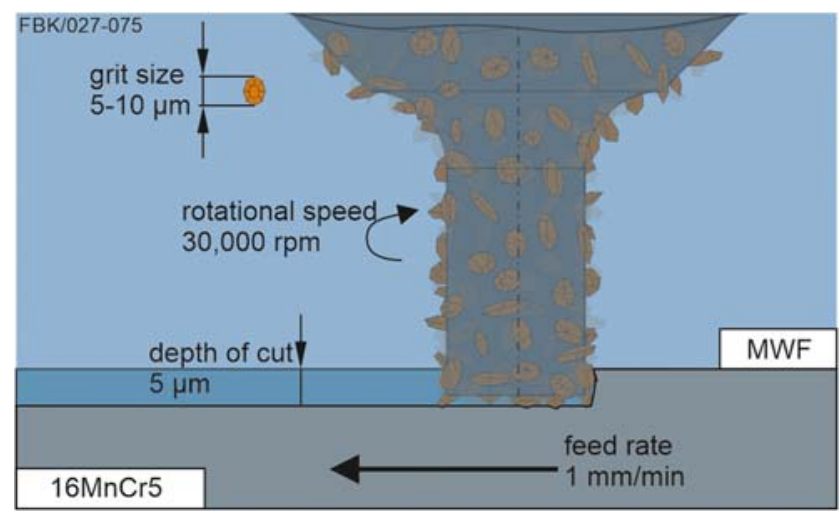

Fig. 2 Process kinematics 
Table 1 MWFs used for submerged micro grinding experiments

\begin{tabular}{|c|c|c|c|}
\hline MWF & Manufacturer $^{\mathrm{a}}$ & Basis & $\begin{array}{l}\text { Kinematic viscosity } \\
\text { at } 20^{\circ} \mathrm{C} \text { in } \mathrm{mm}^{2} \mathrm{~s}^{-1}\end{array}$ \\
\hline Twinmax & Steidle $\mathrm{GmbH}$ & Plant & $180[24]$ \\
\hline Lubrimax Edel C & Steidle $\mathrm{GmbH}$ & Plant & $88[24]$ \\
\hline Canola oil & Brökelmann \& Co., & Plant & $78.7[25]$ \\
\hline DiaMond 80 & $\begin{array}{l}\text { Oelmühle GmbH \& Co. } \\
\text { Oelheld GmbH }\end{array}$ & Synthetic & $3[26]$ \\
\hline Petrofer Isocut R10 - HM & $\begin{array}{l}\text { Petrofer Chemie, } \\
\text { H.R. Fischer GmbH + Co. KG }\end{array}$ & Mineral & $10.8\left(\right.$ at $40^{\circ} \mathrm{C}$ ) [27] \\
\hline SDS (1 wt. \%) & - & Water & $\sim 1$ \\
\hline SDS (5 wt. $\%$ ) & - & Water & $\sim 1$ \\
\hline
\end{tabular}

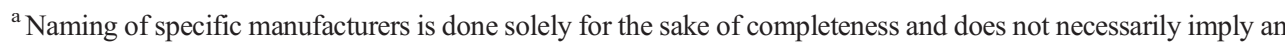
endorsement of the named companies nor that the products are necessarily the best for the purpose.
Three microchannels with a depth of cut of $5 \mu \mathrm{m}$ and a channel length of $3 \mathrm{~mm}$ were machined using each of the MWFs - each channel machined with a new MPGT. A grit size of 5-10 $\mu \mathrm{m}$ with a $5-\mu \mathrm{m}$ thick nickel phosphorous layer was chosen for this study. Relative to the tool substrate diameter, a grit size of $5-10 \mu \mathrm{m}$ is a large grit size, beneficial in terms of tool life and easier to analyze post process. A previous study showed that it is the largest grit size to continually achieve a good grit density on the bottom surface of the tool when using electroless plating for the given tool substrate diameter [21].

\subsection{Process kinematics and experimental plan for pendulum grinding}

An endurance test has been developed to test which MWF is more suitable for this micro grinding process regarding the wear of the tools. The endurance test is similar to a conventional pendulum grinding process, in which a much higher feed rate is applied and multiple, low depth of cut segments that add up to a total channel depth. In conventional grinding, pendulum grinding increases tool wear because the feed rate influences/increases the chip thickness far more than the depth of cut. In contrast, when machining microchannels with MPGTs, the bottom of the tool is mainly used, meaning that different process kinematics take place; the depth of cut directly influences how deep, grits at the bottom and circumference cut into the workpiece. For a grit size of 5-10 $\mu \mathrm{m}$, a smaller depth of cut leaves space for MWF and for better chip transportation. Microchannels machined with a multiple, smaller depth of cut can be machined much faster and much more accurately due to reduced stresses on the abrasive layer, potentially allowing for much deeper channels.

Figure 3 shows a schematic of the process. The depth of cut segments are $0.5 \mu \mathrm{m}$ deep. The feed rate is $30 \mathrm{~mm} / \mathrm{min}$ and the rotational speed is $30,000 \mathrm{rpm}$. The projected channel length is $5 \mathrm{~mm}$ and has a nominal/total channel depth of $50 \mu \mathrm{m}$. A sum of 100 depth of cut segments was machined for each experiment, the actual depth of cut may vary due to tool wear.
In addition to machining the total channel depth in segments, the tool also widens the microchannel by $4 \mu \mathrm{m}$ to increase the flow of MWF into the machining zone (top view in Fig. 3). After the MPGT machines the entire channel length of $5 \mathrm{~mm}$, the MPGT moves $4 \mu \mathrm{m}$ in the orthogonal direction and then back to the starting point, effectively having a rectangular feed movement.

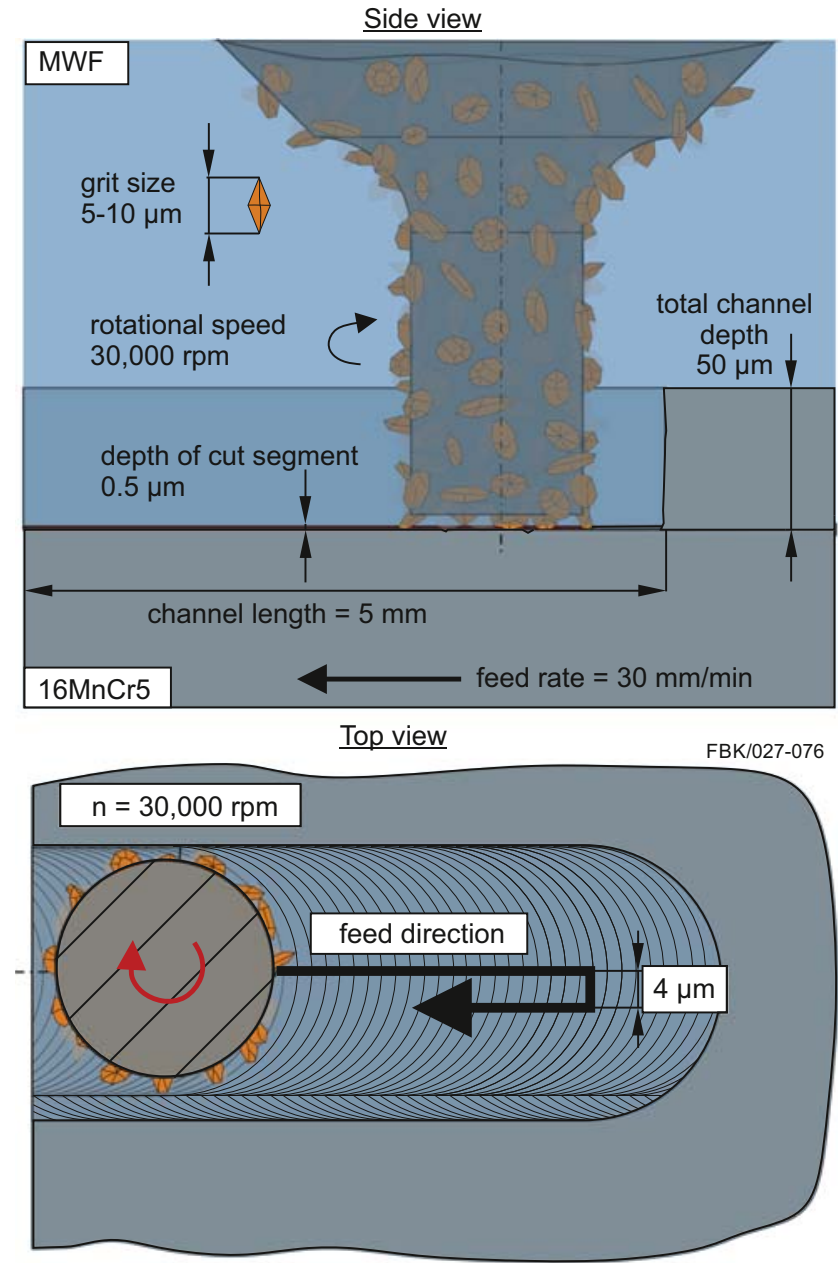

Fig. 3 Micro pendulum grinding process 
Compared with MPGTs with smaller grit sizes and larger grinding tools, only a limited amount of abrasive grits are coated on the bottom of the tool. While larger grit sizes improve the performance of MPGTs exponentially, they cause a high standard deviation to occur. Hence, eight microchannels were machined using each MWF to achieve a higher statistical coverage.

\section{Adhesion measurements}

Images of MPGTs and their respective microchannels were captured using a scanning electron microscope (SEM). An areal material analysis via X-ray spectroscopy (EDX) was done to characterize the material adhesions on the abrasive layer. Iron adhesions were measured to indicate the percentage of adhesions on the bottom surface of MPGTs. Adhesions cannot be quantified in most cases as they depend on the position, the density, and the wear of the grits on the abrasive layer. In addition, adhesions might detach from the abrasive layer during the process, making it even harder to determine the exact amount. Figure 4 shows the area the measurements were conducted in (red circle). In this example, three measurements were performed to demonstrate the discrepancy between different areas on an abrasive layer. The adhesions at the pivot have detached from the MPGT displayed in the figure, reducing the iron adhesions to $2.33 \mathrm{wt} . \%$ at the first sample (marked in Fig. 4). In the second sample, the iron adhesions are 83.09 wt. $\%$ and in the third sample $58.6 \mathrm{wt} . \%$. The marked area has $29.46 \pm 2.22 \mathrm{wt} . \%$ iron adhesions, a number that was highly influenced by detached adhesions during the process. The measured tool was used with SDS (1 wt.\%), the other two tools reached $26.3 \pm 1.58 \mathrm{wt} . \%$ and $15.99 \pm 0.74 \mathrm{wt} . \%$ adhesions.

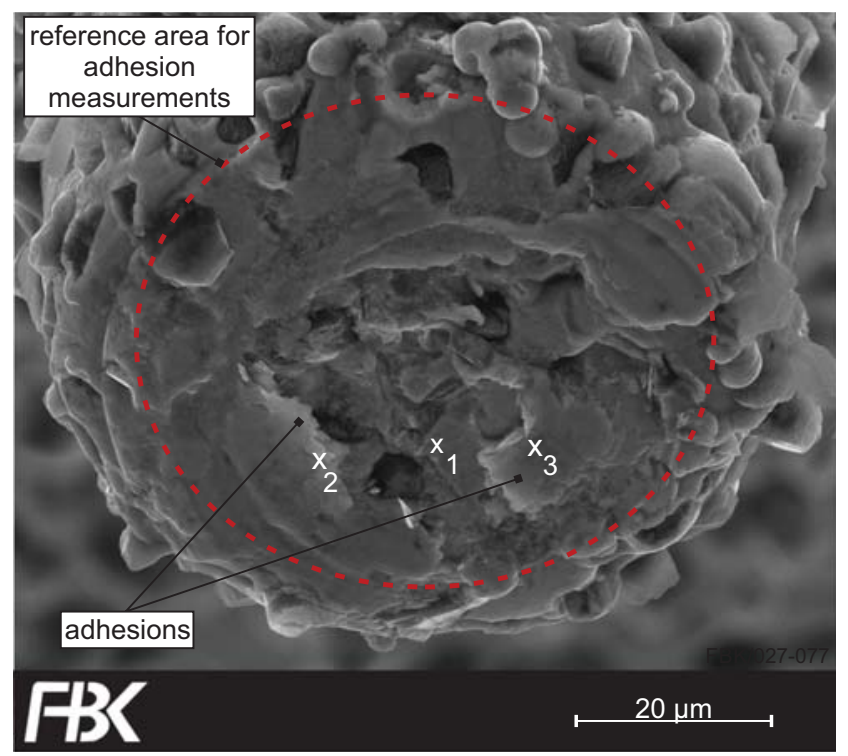

Fig. 4 Reference area for adhesion measurements
Table 2 lists iron adhesion measurements conducted on the bottom of the MPGTs. The entire bottom surface was selected manually and measured via EDX - each measurement was repeated three times. While there is a huge standard deviation between tools used with the same MWF, two out of the three tools used with Twinmax and Lubrimax Edel C stood out, as iron adhesions below $10 \%$ were measured on them. Another surprising development is that the MWF SDS (5 wt.\%) concentration performed worse than SDS (1 wt.\%).

\section{Micro grinding experiments to compare different MWFs}

Figure 5 illustrates MPGTs before and after machining with six of the MWFs. As proven earlier, SDS (1 wt.\%) performs better than SDS (5 wt.\%), so only one SDS (1 wt. \%) is added to the figure. SDS (5 wt.\%), DiaMond 80, and Petrofer Isocut R10 - HM performed similarly. After a channel length of $3 \mathrm{~mm}$, material adhesions covered the bottom surface of the MPGTs, reducing their grit protrusion. One of the MPGTs used for Petrofer Isocut R10 - HM and one used for DiaMond 80 had partial tool failure, losing a small grit population. Canola oil and SDS (1 wt.\%) achieved less material adhesions than the previous three MWFs, allowing for better grit protrusion. Twinmax and Lubrimax Edel $C$ seem to have the least amount of adhesions. The depicted MPGT that was used with Lubrimax Edel C appears to have more damage on the nickel binder than the MPGT used with Twinmax, but this could be due to less advantageous grit distributions.

In terms of material adhesions, the best results appeared when MPGTs were used with MWFs that have a higher viscosity. Viscosity describes the resistance a fluid has to shear and tensile stress. Informally this is defined as "thickness" for liquids [28]. It is assumed that due to this "thickness," MWFs with higher viscosity have higher lubricity and higherpressure absorption capacity. A very resistant lubricating film is built between abrasive grits and the workpiece surface, minimizing ensuing temperatures that result from friction. Canola oil is a MWF that has a high viscosity but no additives, which

Table 2 Iron adhesions measured via EDX on the bottom of MPGTs

\begin{tabular}{llll}
\hline & Tool 1 & Tool 2 & Tool 3 \\
\hline Twinmax & $5.56 \pm 0.37$ & $7.23 \pm 1.56$ & $39.95 \pm 0.61$ \\
Lubrimax Edel C & $26 \pm 0.45$ & $3.24 \pm 0.38$ & $5.04 \pm 0.21$ \\
Canola oil & $23.62 \pm 3.42$ & $38.98 \pm 1.15$ & $12.55 \pm 1.66$ \\
DiaMond 80 & $39.86 \pm 6.35$ & $58.18 \pm 0.44$ & $14.7 \pm 1.92$ \\
Petrofer Isocut R10 - HM & $51.18 \pm 1.63$ & $48.73 \pm 2.19$ & $25.38 \pm 6.27$ \\
SDS (1 wt.\%) & $29.49 \pm 2.22$ & $26.3 \pm 1.58$ & $15.99 \pm 0.74$ \\
SDS (5 wt.\%) & $36.3 \pm 3.39$ & $40.45 \pm 2.13$ & $38.79 \pm 2.31$ \\
\hline
\end{tabular}




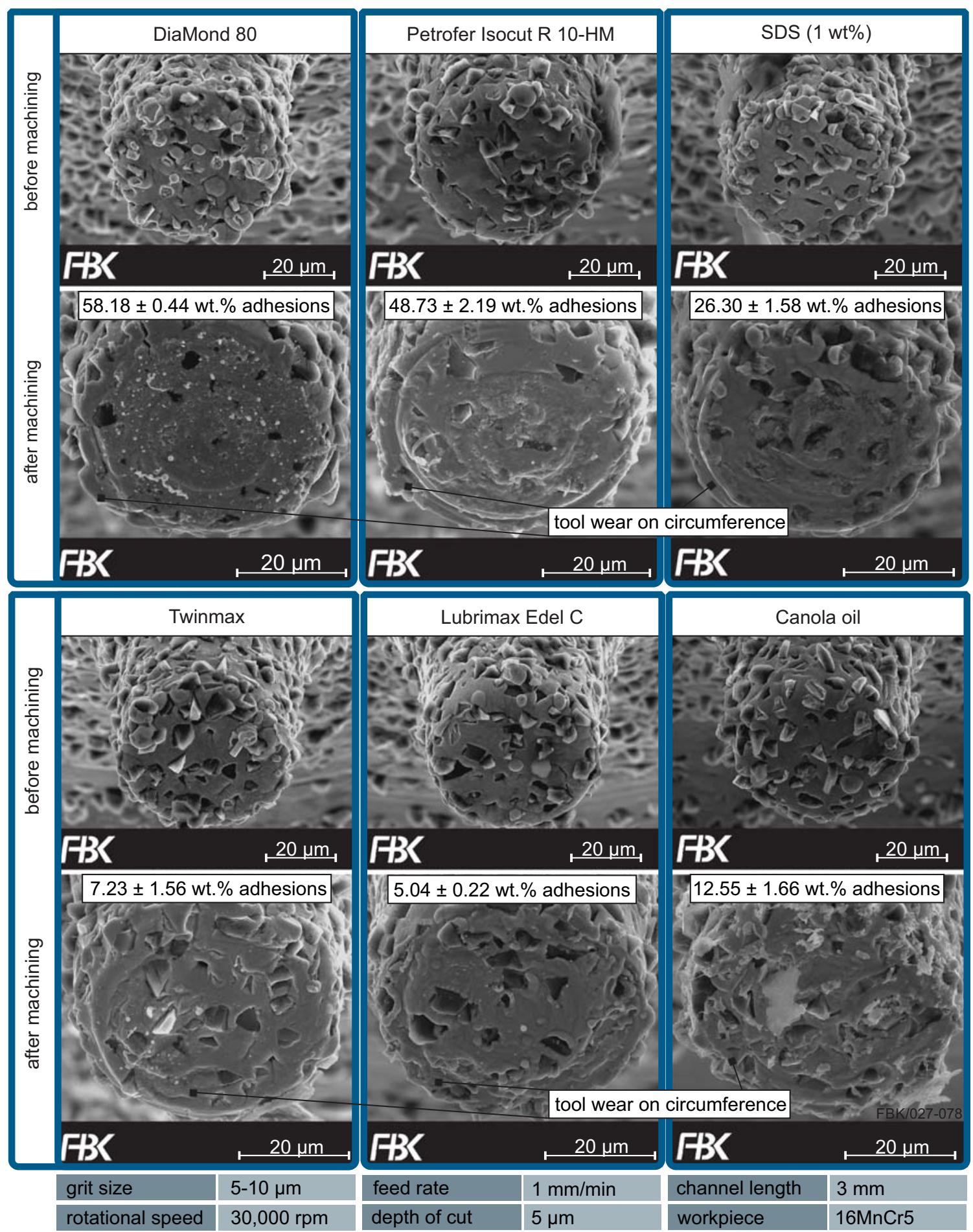

Fig. 5 Exemplary MPGT tool wear using each of the MWFs

is why it performed worse than Twinmax and Lubrimax Edel $C$. Canola oil was also slightly outperformed by using SDS (1 wt.\%). SDS is a surfactant that reduces surface tension and increases wettability. MPGTs have a rather small chip space, which means that an improved wettability and decreased surface tension promotes the ability of the MWF to enter the contact zone. Increasing the SDS concentration to $5 \mathrm{wt}$. $\%$ increases wettability and decreases surface tension further; however, it increases foaming during the process. When a MWF foams, gas is added to its micelles, which decreases the amount of liquid that enters the contact zone.

Grits at the pivot are mostly worn by abrasive wear as they exhibit a much lower cutting speed, shifting the cutting mechanism closer to a scratch test than to a cutting operation. All 
grits along the outer circumference of the tools exhibit decreasing grit protrusions due to abrasive wear, grit fracture, and attrition. As the grits on the circumference cut the most material per rotation, they are much more prone to grit fracture because of high mechanical impacts. The tools presented in Fig. 5, demonstrate the intense tool wear on the circumference. The worn-down area does not encompass the entire circumference of the tool due to the influence of run-out error that is caused by re-clamping the shaft of the tool.

\section{Pendulum grinding}

The experiments were conducted for the two MWFs that caused the least adhesions on the bottom of MPGTs: Twinmax and Lubrimax Edel C. Figure 6 shows the achieved channel depths for every experiment conducted with each of the two MWFs. In experiments performed with Twinmax, a total channel depth of $35.9 \mu \mathrm{m} \pm 13.2 \mu \mathrm{m}$ was measured and a total channel depth of $33.3 \mu \mathrm{m} \pm 10.4 \mu \mathrm{m}$ for those conducted with Lubrimax Edel C. While similar in terms of the values, Twinmax proved to be the slight favorite as four out of the eight tools used for the experimental series were still intact after machining the entire channel depth. In contrast, only two MPGTs remained intact with Lubrimax Edel C.

Figure 7 shows one of the microchannels and the MPGT that was used in its machining process. The microchannel shows smeared grinding marks and a smeared substructure in the middle of the channel. The substrate material of the MPGTs is not hard enough to remove material. Therefore, once the abrasive layer breaks, the material is not removed, but the roughness peaks are ploughed and squeezed. The MPGT shown in Fig. 7 lost its abrasive layer and appears to have been flattened during the process.

On the other hand, when an MPGT succeeds in completing the 100 cycles while still intact, microchannels show substructures and grinding marks, Fig. 8 shows an exemplary

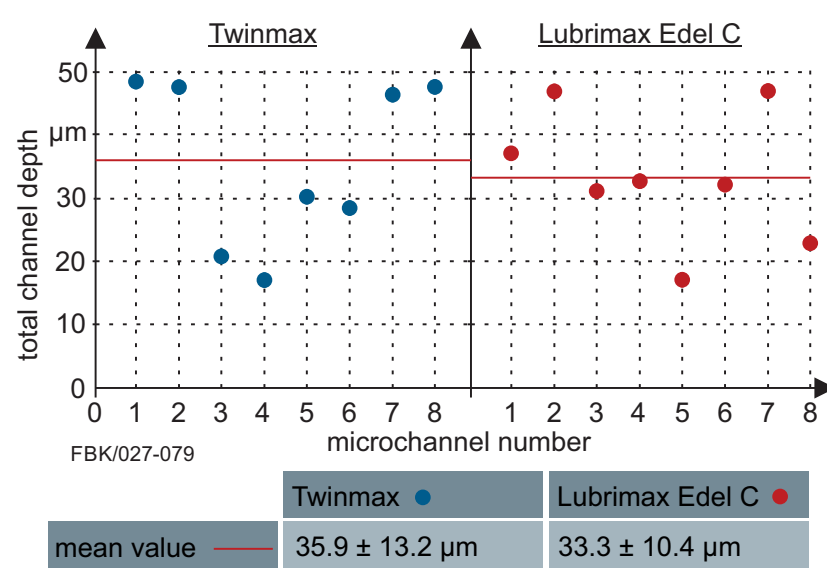

Fig. 6 Pendulum grinding experiment showing total depth of channel for each pendulum grinding experiment microchannel. The microchannel is wider at the top because tool wear reduces the diameter of the tool. Substructures and grinding marks occur because each tool is unique, each abrasive layer has a different grit density, different grit positions with different grit embedment. Substructures are smaller channels at the bottom of machined microchannels that are caused by the different protrusions of grits that are located in different positions on the bottom of MPGTs. Tool wear at the circumference caused the width of the microchannel to decrease towards the bottom. Grinding marks are formed by the grit with the highest protrusion. Similar to feed per rotation, grinding marks have an almost constant distance that is mainly influenced by the rotational speed and the feed rate - in this case, a distance of $1 \mu \mathrm{m}$ can be measured between two grinding marks.
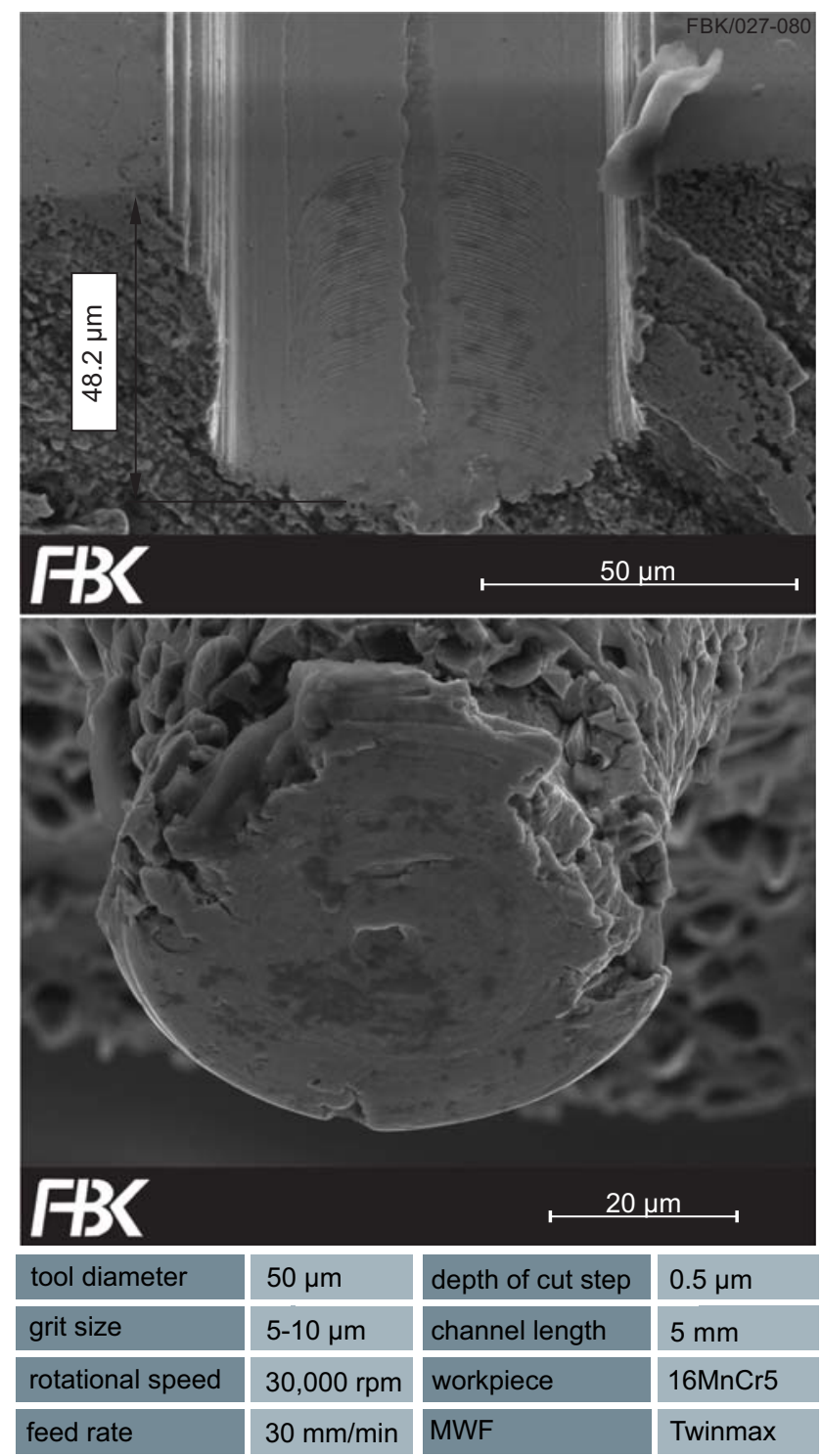

Fig. 7 SEM image of a 5-mm long microchannel, machined with micro pendulum grinding and MPGT post machining 


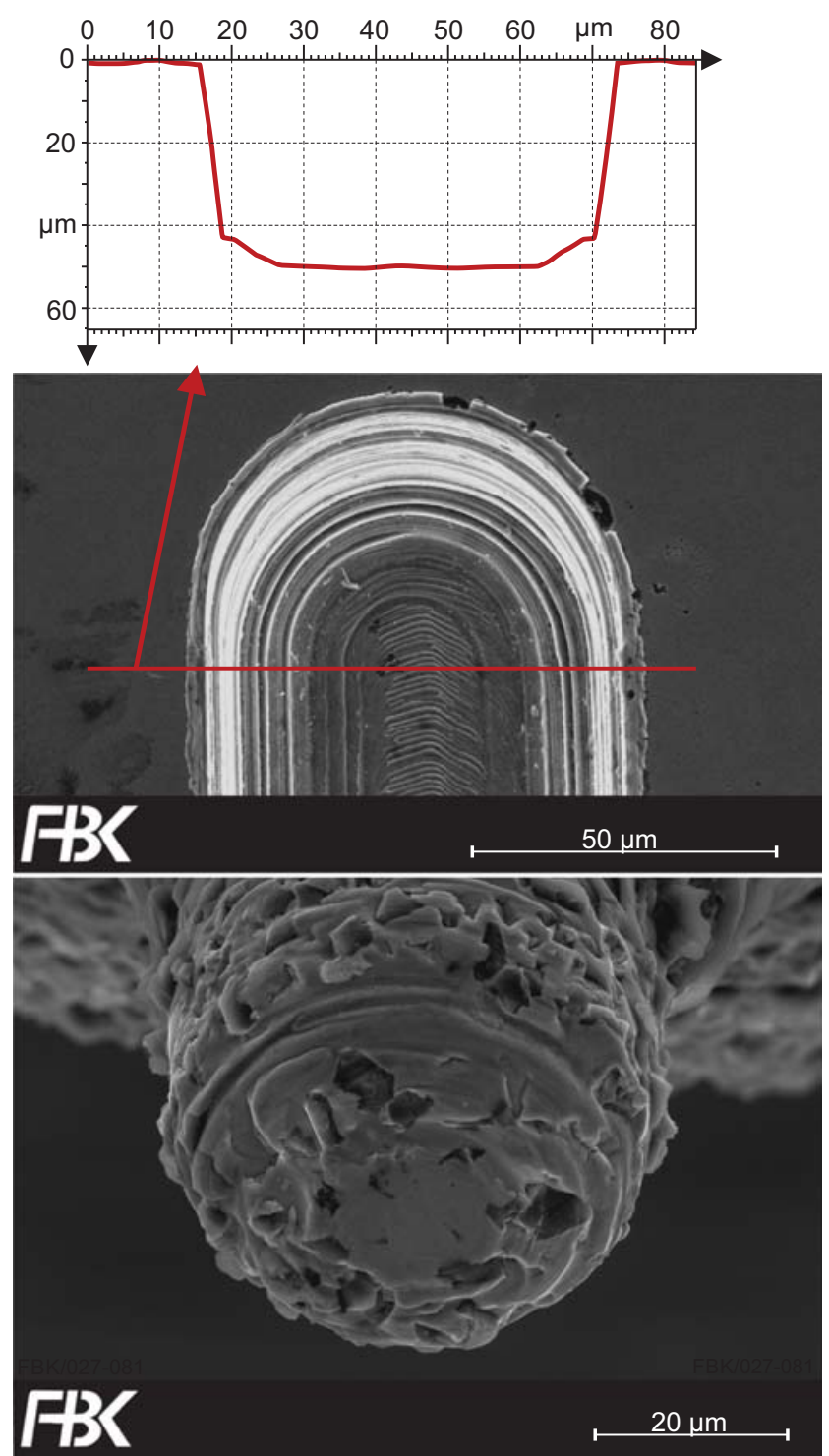

Fig. 8 SEM image of substructures and grinding marks in microchannel

\section{Conclusions}

Micro grinding with MPGTs is a process with a lot of potential when it comes to machining complex structures. A major problem is the rather short tool life, especially with tools of diameters $50 \mu \mathrm{m}$ or less. Previous experiments in which steel workpieces were machined showed that high amounts of adhesions can clog the abrasive layer of the tool, eventually causing tool failure. Generally, this problem occurs due to poor lubrication. In order to solve this issue, a submerged micro grinding process was developed. Additionally, to further improve the process, a new micro grinding methodology was developed: micro pendulum grinding.

First, 3-mm long channels with a depth of cut of $5 \mu \mathrm{m}$ were machined with a feed rate of $1 \mathrm{~mm} / \mathrm{min}$ and a rotational speed of $30,000 \mathrm{rpm}$. The submerged micro grinding process was conducted with seven different MWFs. The results showed that when using some of the more viscose MWFs like Twinmax, and Lubrimax Edel C, decisively less adhesions formed, showing only regular abrasive wear on the bottom of the tool. A micro pendulum grinding process was developed. A process in which the tool produces its projected channel depth in smaller segments at a much higher feed rate. In addition, while moving back to the start position of the channel, the tool increases the channel width by $4 \mu \mathrm{m}$ after each depth of cut segment, to allow for more MWF to reach the machining zone.

Using the new submerged micro pendulum grinding process, Twinmax and Lubrimax Edel C were compared in a tool life experiment. In this experiment, the tool was set to machine a $5 \mathrm{~mm}$-long and $50-\mu \mathrm{m}$ deep microchannel, at a feed rate of $30 \mathrm{~mm} / \mathrm{min}$ and a rotational speed of 30,000 rpm. Twinmax became the slight favorite reaching $35.9 \mu \mathrm{m} \pm 13.2 \mu \mathrm{m}$ in total channel depth with four tools still intact, while Lubrimax Edel $C$ reached a total channel depth of $33.3 \mu \mathrm{m} \pm 10.4 \mu \mathrm{m}$ with two tools still intact.

Both submerged micro grinding and micro pendulum grinding improved the process tremendously, making it possible for MPGTs with diameters of $\sim 50 \mu \mathrm{m}$ to reach microchannel aspect ratios of $>1$, while also making complex structures possible. In future investigations, additional submerged micro grinding experiments with different MWFs will be conducted to reach even higher tool lives. As seen with Twinmax, MWFs with a higher viscosity seem to have an edge in this type of micro grinding process. More data is needed to validate the relationship between viscosity and tool life.

Funding information This research was funded by the Deutsche Forschungsgemeinschaft (DFG, German Research Foundation), Project number 172116086-SFB 926. Open Access funding provided by Projekt DEAL.

Open Access This article is licensed under a Creative Commons Attribution 4.0 International License, which permits use, sharing, adaptation, distribution and reproduction in any medium or format, as long as you give appropriate credit to the original author(s) and the source, provide a link to the Creative Commons licence, and indicate if changes were made. The images or other third party material in this article are included in the article's Creative Commons licence, unless indicated otherwise in a credit line to the material. If material is not included in the article's Creative Commons licence and your intended use is not permitted by statutory regulation or exceeds the permitted use, you will need to obtain permission directly from the copyright holder. To view a copy of this licence, visit http://creativecommons.org/licenses/by/4.0/.

\section{References}

1. Park HW (2008) Development of micro-grinding mechanics and machine tools. Georgia Institute of Technology

2. Feng J (2010) Microgrinding of ceramic materials

3. Schlautmann S, Wensink H, Schasfoort R, Elwenspoek M, Berg Av-d (2001) Powder-blasting technology as an alternative tool for 
microfabrication of capillary electrophoresis chips with integrated conductivity sensors. Institute of Physics

4. Cheng K, Huo D (2013) Micro cutting: fundamentals and applications. Wiley, Chichester

5. Bohley M, Kieren-Ehses S, Heberger L, Kirsch B, Aurich JC (2018) Size limitations and wear behavior of TiB2 coated micro end mills $(\varnothing<50 \mu \mathrm{m})$ when machining cp-titanium. In: 4th CIRP Conference on Surface Integrity, p. 187-191

6. Ohnishi O, Onikura H, Aziz M (2006) The effects of ultrasonic vibration on micro drilling performance with a diameter of $5 \mu \mathrm{m}$ into titanium alloy. In: Proceedings of the 6th euspen international conference, Baden, Austria

7. Wenda A (2002) Schleifen von Mikrostrukturen in sprödharten Werkstoffen. Essen, Vulkan-Verl

8. Lee SB, Tani Y, Enomoto T, Sato H (2005) Development of a dicing blade with photopolymerizable resins for improving machinability. CIRP Ann 54(1):293-296. https://doi.org/10.1016/S00078506(07)60106-1

9. Hoffmeister H-W, Hlavac M (2002) Schleifen von Mikrostrukturen. Tagungsband des 10. Feinbearbeitungskolloqiums in Braunschweig 2002:7.1-7.24

10. Arrabiyeh PA, Heintz M, Kirsch B, Aurich JC (2019) Custom made electroless plated dicing blades for micro machining operations. In: euspen's 19th International Conference \& Exhibition. Bilbao, Spain, p. 380-383

11. Arrabiyeh PA, Kirsch B, Aurich JC (2018) Electroless plating and application of micro pencil grinding tools with a diameter of $5 \mu \mathrm{m}$. In: euspen's 18th International Conference, p. 309-310

12. Klocke F (2009) Manufacturing processes 2: grinding, honing, lapping. Springer-Verlag, Berlin

13. Li K-M, Lin C-P (2012) Study on minimum quantity lubrication in micro-grinding. Int J Adv Manuf Technol 62(1-4):99-105. https:// doi.org/10.1007/s00170-011-3789-1

14. Fritz AH, Schulze G (2008) Fertigungstechnik, 8th edn. SpringerVerlag, Berlin

15. Arrabiyeh PA, Bohley M, Ströer F, Kirsch B, Seewig J, Aurich JC (2017) Experimental analysis for the use of sodium dodecyl sulfate as a soluble metal cutting fluid for micromachining with electrolessplated micropencil grinding tools. Inventions:2(29). https://doi.org/ 10.3390/inventions2040029
16. Kieren-Ehses S, Bohley M, Arrabiyeh PA, Kirsch B, Aurich JC (2018) Influence of different metal working fluids when micro machining cp-titanium with $50 \mu \mathrm{m}$ diameter micro end mills Article. In: 4th CIRP Conference on Surface Integrity (CSI 2018)

17. König W (1980) Schleifen, Honen, Läppen. VDI-Verlag, Düsseldorf

18. Klocke F, Eisenblätter G (1997) Dry cutting. CIRP Ann Manuf Technol 46(2):519-526

19. Nam JS, Kim DH, Chung H, Lee SW (2015) Optimization of environmentally benign micro-drilling process with nanofluid minimum quantity lubrication using response surface methodology and genetic algorithm. J Clean Prod 102:428-436. https://doi.org/10. 1016/j.jclepro.2015.04.057

20. Pham M-Q, Yoon H-S, Khare V, Ahn S-H (2014) Evaluation of ionic liquids as lubricants in micro milling-process capability and sustainability. J Clean Prod 76:167-173. https://doi.org/10.1016/j. jclepro.2014.04.055

21. Kirsch B, Bohley M, Arrabiyeh PA, Aurich JC (2017) Application of ultra-small micro grinding and micro milling tools: possibilities and limitations. Micromachines 8(9):261-279. https://doi.org/10. 3390/mi8090261

22. Zhang GM, Ko WF, Stanley N (1995) Submerged precision machining of ceramic material. Technical Research Report

23. Brudek G, Wulfsberg JP (2007) Kühlschmierung beim Mikrofräsen. Berichte aus dem Institut für Konstruktions- und Fertigungstechnik, 8

24. Steidle GmbH. https://www.steidle-gmbh.de/

25. Spicher U, Lüft M (2007) Optimierung der Kraftstoffstrahlausbreitung für Pflanzenöl, insbesondere natürliches Rapsöl, bei der Verwendung moderner Diesel-Einspritzsysteme. University of Karlsruhe: Institut für Kolbenmaschinen

26. oelheld GmbH. http://www.oelheld.de/

27. PETROFER CHEMIE H. R. Fischer GmbH + Co. KG. https:// www.petrofer.com/de/

28. Symon KR. Mechanics. Estados Unidos: Addison-Wesley Publishing Company, Inc; C1971

Publisher's note Springer Nature remains neutral with regard to jurisdictional claims in published maps and institutional affiliations. 